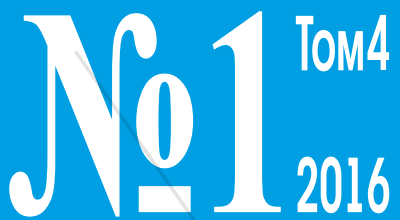

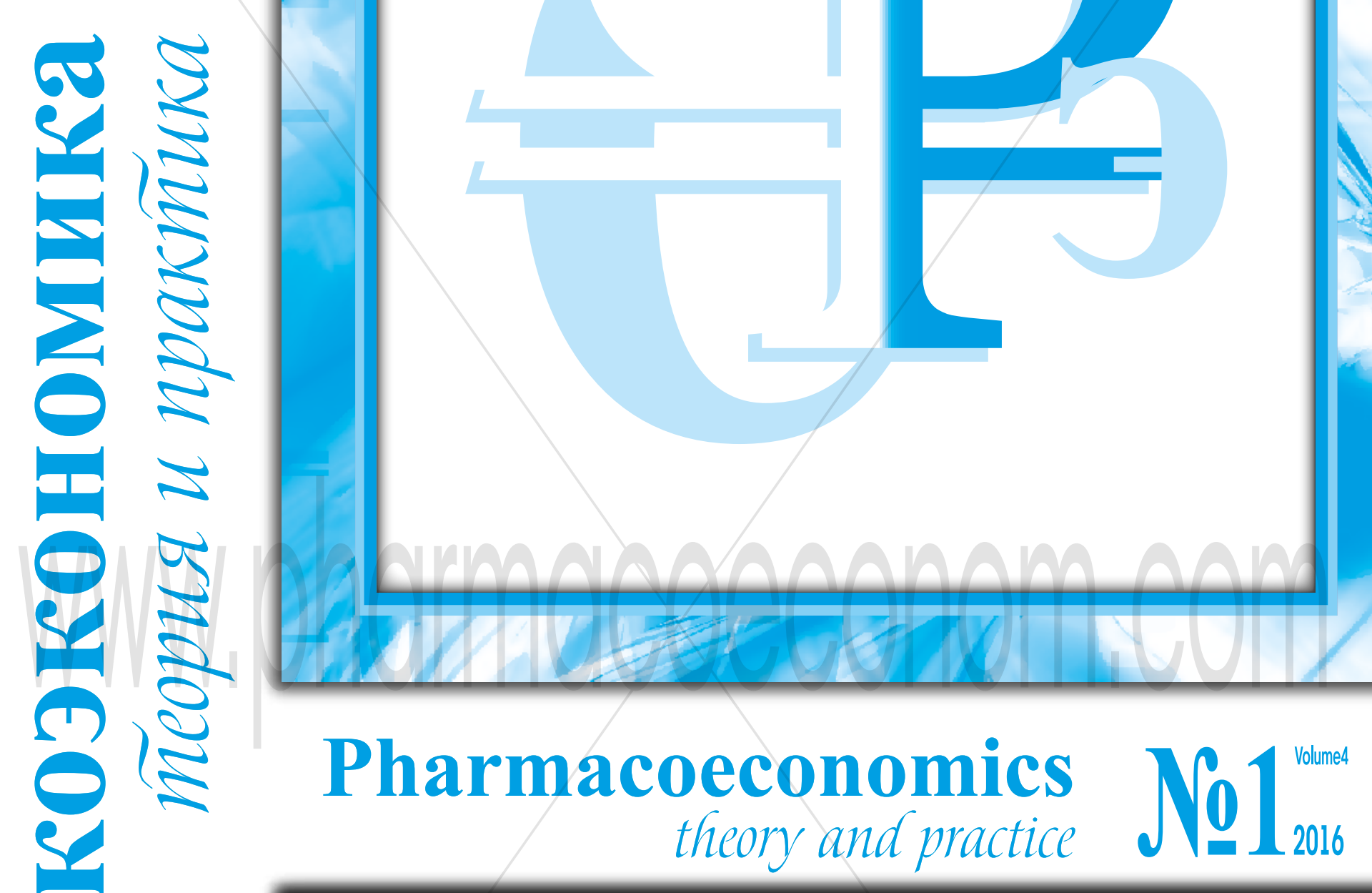

$\square$ МЕТОДОЛОГИЧЕСКИЕ ОСНОВЫ ФАРМАКОЭКОНОМИЧЕСКОГО МОДЕЛИРОВАНИЯ

$\square$ РЕЗУЛЬТАТЫ РОССИЙСКИХ ФАРМАКОЭКОНОМИЧЕСКИХ ИССЛЕДОВАНИЙ

口 МАТЕРИАЛЫ Х НАЦИОНАЛЬНОГО КОНГРЕССА С МЕЖДУНАРОДНЫМ УЧАСТИЕМ «РАЗВИТИЕ ФАРМАКОЭКОНОМИКИ И ФАРМАКОЭПИДЕМИОЛОГИИ В РОССИЙСКОЙ ФЕДЕРАЦИИ» 4-5 апреля 2016 г., г. Нижний Новгород 


\title{
PHARMACOECONOMIC EVALUATION OF DABRAFENIB IN PATIENTS WITH UNRESECTABLE OR METASTATIC MELANOMA WITH BRAF V600 MUTATION
}

\author{
Kulikov A.Yu. Pochuprina A.A.
}

\section{I.M. Sechenov First Moscow State Medical University of the Ministry of Health of the Russian Federation}

\begin{abstract}
:
Pharmacoeconomic evaluation of patients with BRAF mutation-positive melanoma treatment with dabrafenib and vemurafenib was conducted in the present study. When analyzing the costs required per one year of the therapy with the drugs being compared, it was established that treatment with dabrafenib was $28 \%$ less expensive in comparison with vemurafenib, and the differences in the cost per patient per year was 1,633,622 RUB. The budget impact analysis has shown that dabrafenib comparing to vemurafenib treatment to may reduce budget costs by 1,268,108 RUB per patient within first one year. The results based on data from previous clinical studies have shown that treatment with dabrafenib reduces costs by $35 \%$ as compared to the therapy with vemurafenib. Analysis demonstrated that throughout the projected cohort of patients (1245 patients), requiring BRAF-kinase inhibitors treatment, dabrafenib treatment allows to treat additional 680 patients in comparison with vemurafenib within the period before the beginning of progression. Therefore, dabrafenib therapy is preferred treatment option for patients with BRAF mutation-positive advanced and unresectable melanoma in Russian Federation.
\end{abstract}

Key words: dabrafenib, vemurafenib, dacarbazine, melanoma, unresectable and metastatic melanoma, BRAF V600 gene mutation, post-progression survival, progression-free survival, overall survival, inhibitors of BRAF-kinases, pharmacoeconomics, cost-minimization analysis, budget impact analysis, missed opportunity analysis.

\section{Introduction}

Melanoma is one of the most aggressive forms of skin cancer, which develops from melanocytes, pigment synthesizing cells that can be found throughout the body, including the skin, mucosals, and iris [22, 25, 30]. Cutaneous types of melanoma, found in $90 \%$ of cases, are the most common and well-investigated [1]. The incidence of melanoma is increasing worldwide by $3-5 \%$ every year $[4,32]$, which is also confirmed by data in Russia: its prevalence in Russia increased by $5.8 \%$ in 2014 compared to 2013 and by $51.8 \%$ compared to 2004 (Figure 1) [2]. According to P. Herzen Moscow Oncology Research Institute data, the number of patients with newlydiagnosed melanoma was registered in 9,390 patients. [3]

Melanoma estimates about $2 \%$ of all skin tumors [3,32]. Meanwhile, being one of the most aggressive forms of cancer, melanoma is characterized by a high mortality rate, which accounts for $75 \%$ of all skin cancer cases [ 4 , $18,25]$. According to Russian epidemiologic data, the annual mortality rate of melanoma in 2014 was $12.1 \%$. The results presented show a steady tendency to decrease of this rate over the last 10 years. This trend is due to improved diagnosis of the disease and implementation of innovative approaches to treatment (Figure 2) [2]. At the same time, the risk of death increases with the severity of disease, and staging process. Thus, in patients with stage IIIC, the 5 -year survival rate is only $40 \%, 10$-year-old - $24 \%$, while patients with stage IV have mortality rate of $15 \%-20 \%$ and $10-15 \%$, respectively [34].

Approximately $50-60 \%$ of patients with melanoma have the BRAF gene mutation, which leads to simultaneous uncontrolled cell proliferation and increased survival due to hyper activation of the mitogen-activated protein kinase pathway. A high significance of the above gene mutation in the mechanism underlying melanoma led to the development of drugs with targeted inhibitory activity against this level of pathogenesis $[3,4]$.

Patients diagnosed with BRAF-positive unresectable or metastatic melanoma, according to the recommendations of the Association of oncologists of Russia should be prescribed with BRAF inhibitor therapy-kinases (dabrafenib and vemurafenib) before progression of the disease [3]. Randomized phase III clinical trials demonstrated that these drugs were markedly more effective in patients with unresectable or metastatic cutaneous melanoma with BRAF V600 mutation compared with dacarbazine. Efficacy measures were progression-free survival (PFS) and overall survival (OS) [27, 29].

Early stages of melanoma require surgical excision of the tumor tissue, and unresectable or metastatic cases should be treated with chemotherapy [1] that, consequently, affects the cost of treatment. For example, D.T. Alexandrescu et al. found that direct costs on treatment per one case of early stage $\mathrm{T} 1$ melanoma for the US health care system in 2009 amounted to $\$ 2,442$, while treatment of a more severe stage T4b required 2.7 times higher costs $(\$ 6,678)$ [15]. Therefore, the more severe disease stages require the higher direct costs. Meanwhile, melanoma leads to the increase of indirect costs related to disability and premature death of patients at working age (an average age of melanoma to be diagnosed is 53 years) [36]. The assessment of the economic burden of metastatic melanoma in Australia in 2014 showed that expenses related to premature mortality of patients with this diagnosis accounted $\$ 202.56 \mathrm{mln}$ (loss of 25,875 healthy life years) [14]. These results indicate that melanoma is a social and economic problem for the entire society and the choice of therapy should be justified both with clinical efficacy and cost effectiveness.

In 2014, about 9,390 new cases of melanoma were diagnosed in the Russian Federation. Almost $25 \%$ of the cases are diagnosed in the late stages with distant metastases [1,3]. It is assumed that $60 \%$ of tumor appearance is associated with the presence of BRAF-mutations [2]. Therefore, the number of patients in the Russian Federation who require treatment with a BRAFinhibitor is about 1,245 (Figure 3). 


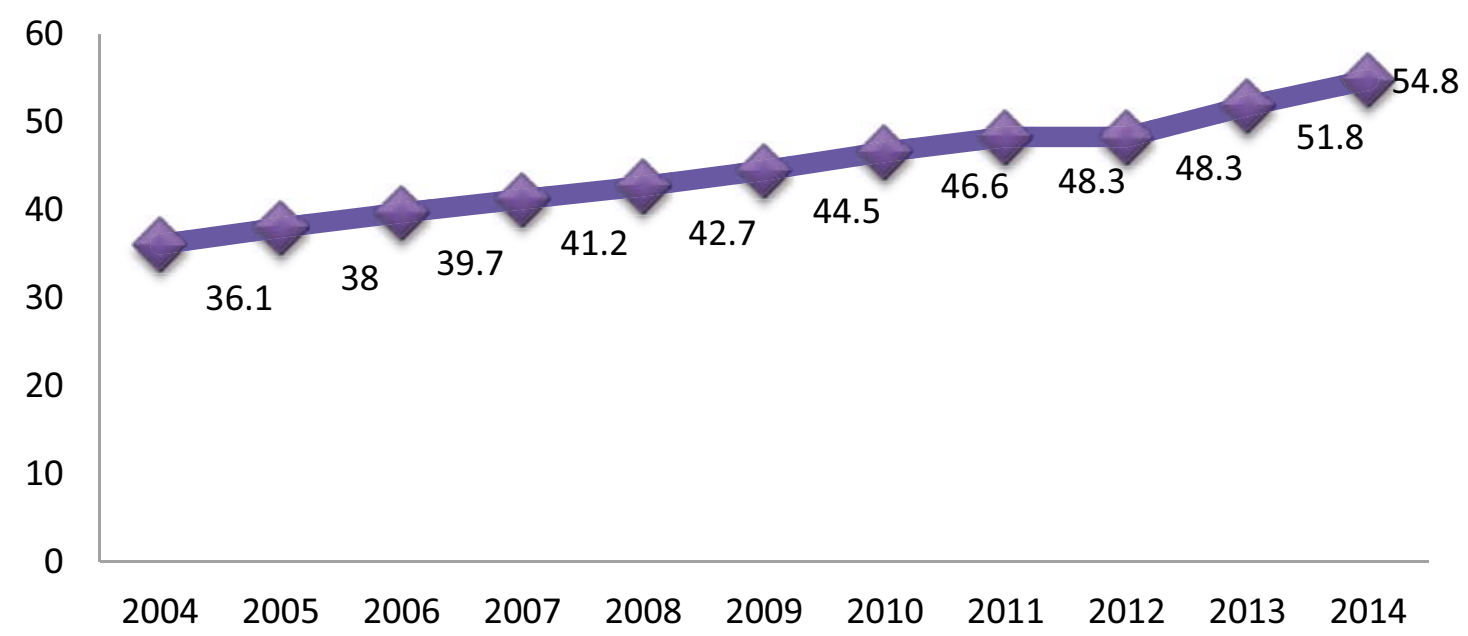

Figure 1. The prevalence of melanoma in the Russian Federation per 100,000 population [3]

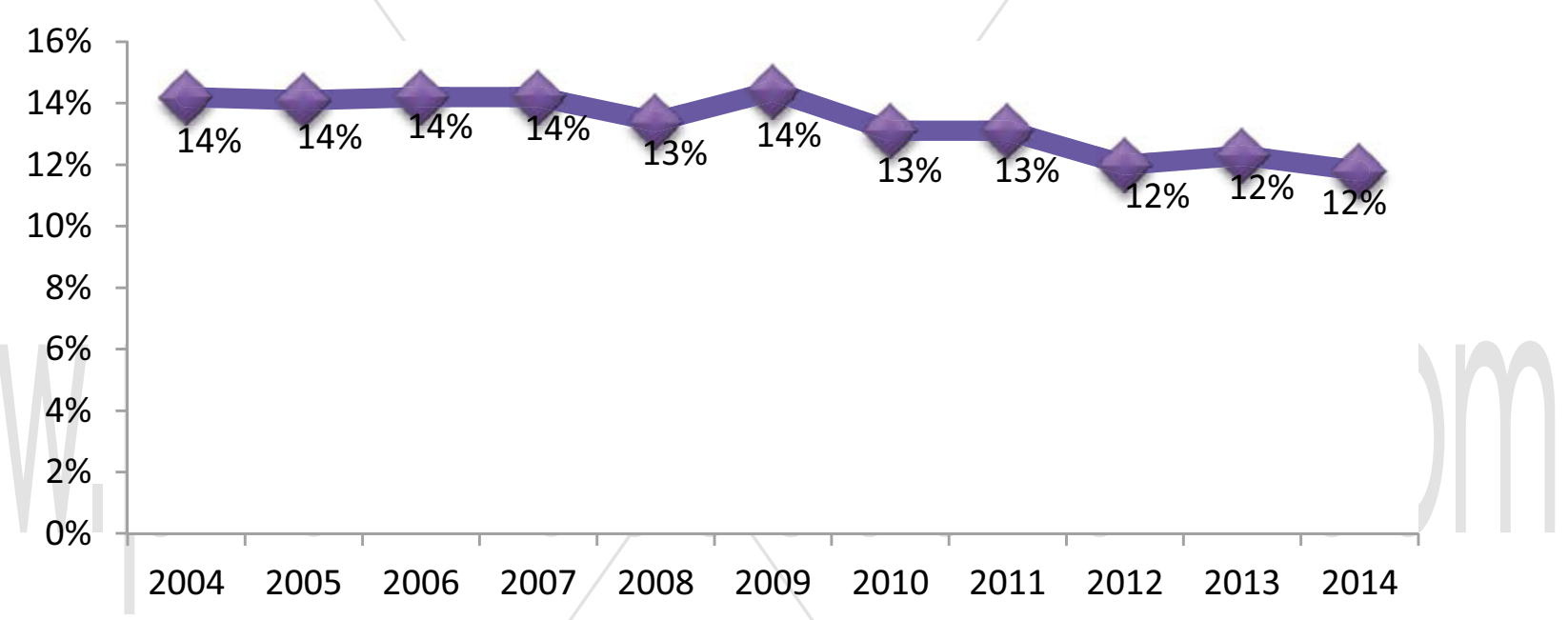

Figure 2. Mortality rates over a year after diagnosis in the Russian Federation, \% [3]

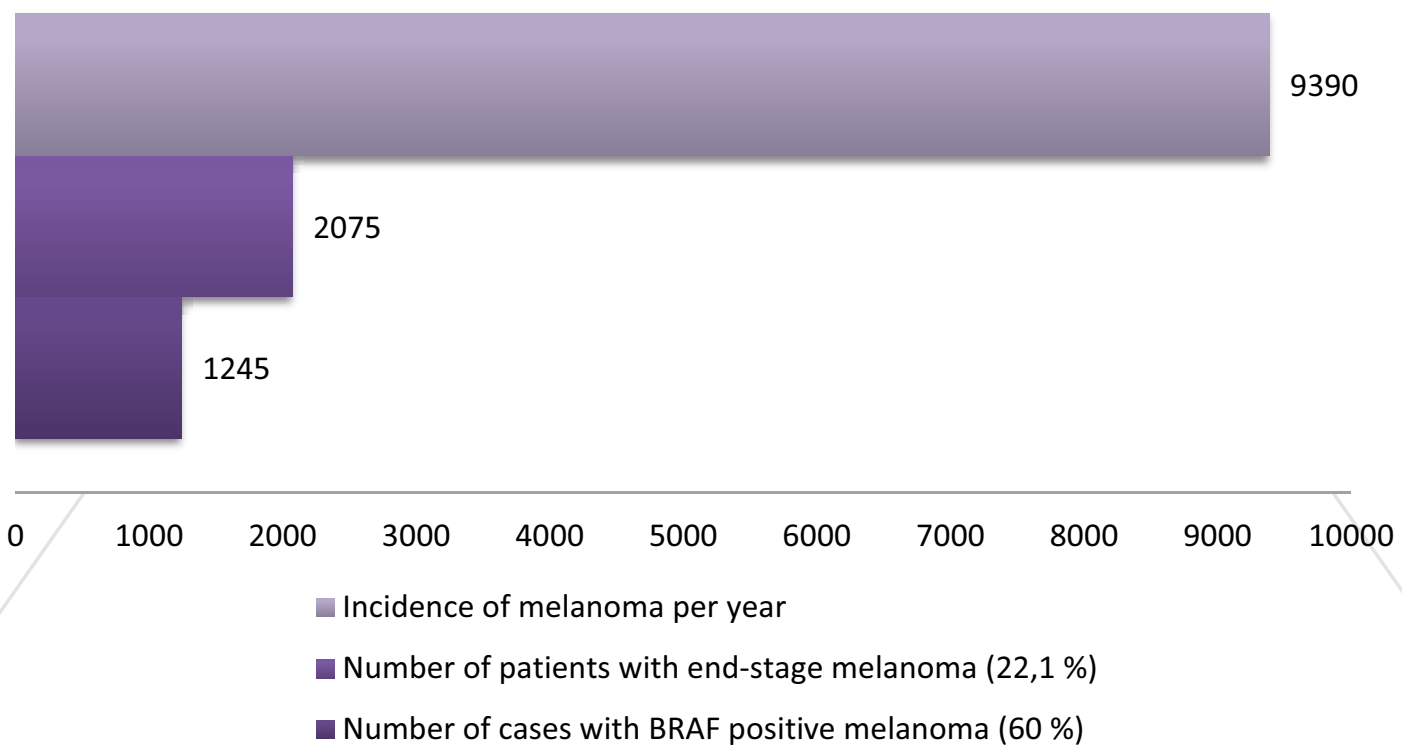

Figure 3. The projected number of patients with metastatic or unresectable melanoma with the BRAF V600 gene mutation 
Currently, BRAF-kinase inhibitors (dabrafenib and vemurafenib) are not included in the Essential drug List (EDL), which limits the possibilities of effective treatment of BRAF-positive melanoma. One of the arguments to include the drugs in the EDL is the result of pharmacoeconomic evaluation [11]. Thus, the pharmacoeconomic research of the innovative drugs dabrafenib and vemurafenib in patients with unresectable or metastatic melanoma with BRAF V600 mutation is needed to use these results for decision-making in the drug supply for these patients.

Experts in various fields, such as public health policy officials, heads of medical institutions and oncologists, will be able to use the results obtained in the pharmacoeconomic study.

\section{Materials and Methods}

In the present research, an analytical model for decision-making was designed in MS Excel, which enables conducting a pharmacoeconomic evaluation of the therapy with dabrafenib vs vemurafenib in patients with unresectable or metastatic melanoma with BRAF V600 mutation.

Clinical and economic analysis was conducted using the following methods of pharmacoeconomic evaluation:

1. The effectiveness analysis

2. Cost analysis

3. Cost-minimization analysis

4. Budget impact analysis

To articulate the effectiveness of the compared treatment options for unresectable or metastatic melanoma with BRAF V600 mutation, Pubmed, Medlink and Cochrane databases were searched to retrieve data using the following key words: dabrafenib, vemurafenib, dacarbazine, trametinib, melanoma, unresectable or metastatic melanoma, BRAF V600 gene mutation, post-progression survival, progression-free survival, overall survival, inhibitors of BRAF-kinases, phase III.

The search yielded two international multicenter, randomized, comparative phase III clinical trials to evaluate the safety and efficacy of dabrafenib (BREAK-3) or vemurafenib (BRIM-3) versus dacarbazine in patients with melanoma, which served as the subject of further investigation (Table 1 ) $[19,20,27,28,35]$.

Table 1. Clinical trials to evaluate the safety and efficacy of dabrafenib or vemurafenib

\begin{tabular}{|c|c|c|c|c|c|c|}
\hline $\begin{array}{c}\text { Test } \\
\text { sub- } \\
\text { stance }\end{array}$ & $\begin{array}{l}\text { Compara- } \\
\text { tor agent }\end{array}$ & $\begin{array}{l}\text { Study } \\
\text { name }\end{array}$ & $\begin{array}{l}\text { Patient } \\
\text { number }\end{array}$ & Follow-up & $\begin{array}{l}\text { Efficacy } \\
\text { measures }\end{array}$ & Source \\
\hline $\begin{array}{l}\text { Dab- } \\
\text { rafenib }\end{array}$ & $\begin{array}{c}\text { Dacarba- } \\
\text { zine }\end{array}$ & BREAK-3 & $\begin{array}{l}\text { 1. } 187 \\
2.67\end{array}$ & $\begin{array}{c}42 \\
\text { months }\end{array}$ & $\begin{array}{l}\text { 1. PFS } \\
\text { 2. OS } \\
\text { 3. Median } \\
\text { PFS } \\
\text { 4. Median } \\
\text { OS }\end{array}$ & [27] \\
\hline $\begin{array}{l}\text { Vemu- } \\
\text { rafenib }\end{array}$ & $\begin{array}{c}\text { Dacarba- } \\
\text { zine }\end{array}$ & BRIM-3 & $\begin{array}{l}\text { 1. } 295 \\
\text { 2. } 303\end{array}$ & $\begin{array}{c}24 \\
\text { months }\end{array}$ & $\begin{array}{l}\text { 1. PFS } \\
\text { 2. OS } \\
\text { 3. Median } \\
\text { PFS } \\
\text { 4. Median } \\
\text { OS }\end{array}$ & [28] \\
\hline
\end{tabular}

Dacarbazine was a shared alternative therapy option in both studies. The patient populations in these two studies were comparable in age and sex, and represented patients with unresectable or metastatic cutaneous melanoma with the BRAF V600 gene mutation. Efficacy was evaluated using the same parameters: PFS, OS, median PFS, median OS (Table 1) [27, 28]. Based on the data obtained, an indirect comparison of treatment with drugs being studied was conducted.

One of the characteristics of the reported studies was a possibility of switching patients to a more effective treatment of dabrafenib BREAK-3 clinical trial, whereas in order to switch patients to a group of more effective treatments it was required approval of Ethics Committee in the study of safety and efficacy assessment of vemurafenib in BRIM-3 trial. Therefore, the presented results of conducted clinical trials show the summarized OS for patients in comparing groups. These results can not be used as parameter of effectiveness in current study because the target population in Russian Federation is patient with the BRAF-kinase treatment within the period before the beginning of progression according prescribing information of comparing drugs and according national recommendation in treatment of patients with melanoma $[1,12,13]$. Data of OS for target population is not available.This is why median PFS was chosen as the main efficacy measure. An additional argument in favor of choosing PFS are the results of a study by K.T. Flaherty et al., which demonstrated that PFS is an acceptable surrogate endpoint with a robust relation to $O S$ in dacarbazine-controlled clinical trials in the treatment of metastatic melanoma [23].

Clinical trials showed similar median PFS of 6.9 months in the dabrafenib and vemurafenib treatment groups, while in the dacarbazine group it was 2.7 months (BREAK-3) and 1.7 months (BRIM-3) (Table 2). Hazard ratios (HR) of PFS in the dabrafenib-dacarbazine and vemurafenib-dacarbazine groups were 0.37 and 0.39 , respectively $[29,35]$, suggesting a relatively similar risk of the events in the two groups being compared to the control treatment with dacarbazine.

Table 2. The efficacy analysis

\begin{tabular}{|c|c|c|}
\hline Outcome measure & Dabrafenib & Vemurafenib \\
\hline Median PFS, months & 6.9 & 6.9 \\
\hline $\begin{array}{c}\text { Hazard Ratio (com- } \\
\text { pared to dacarbazine) }\end{array}$ & 0.37 & 0.39 \\
\hline
\end{tabular}

K. Srivastava et al. obtained similar results when conducting an indirect comparison of the mentioned treatment options based on the data from clinical trials BREAK-3 and BRIM-3 obtained on the earlier stages of observation. The researchers also showed congruity in the events in the two treatment groups (ie dabrafenib and vemurafenib vs other treatments) being compared, which led to the conclusion of a relatively similar efficacy of these methods of therapy [31].

In view of the reported comparable efficacy of the investigated treatment strategies in patients with unresectable or metastatic melanoma with the BRAF V600 gene mutation by the time of progression-free period, an appropriate method for clinical and economic evaluation is a cost-minimization analysis.

In the present study, we calculated only direct medical costs, the structure of which depends on the patient's particular medical status (progression-free). According to the Russian Society of Clinical Oncology guidelines for patients with BRAF-positive melanoma, they require inhibitors of BRAF-kinases, supportive care for occurring adverse events (AE), and outpatient observation every three months $[1,9]$.

To calculate the costs of treatment, we took into account the average auction prices of the compared drugs as of November 26, 2015. For dabrafenib (Tafinlar ${ }^{\circledR}$ ), we took an average price of 348194 RUB per package (75 mg, 120 pcs), according to the results of government procurement for the period January 31,2015 - January 31,2016 . The same approach was used to determine the price of the reference drug vemurafenib (Zelboraf ${ }^{\circledR}$ ), which was 112780 RUB per package $(240 \mathrm{mg}, 56 \mathrm{pcs})$. The cost of a treatment course is calculated per patient taking into account dosing regimen specified in the prescribing information, as well as data on the probability of duration of progression-free status of patients at the moment for every subsequent two months of therapy. The probability of a patient's progression-free status was estimated based on data on PFS according to the results of randomized clinical trials BRIM-3 and BREAK-3 which was calculated every 2 months before progression the maximum period of which in accordance with clinical trial was 20 months [28, 33].

When assessing the supportive care of adverse events (AEs) and serious AEs, cost of each case was determined by the approved health care standards and guidelines for treatment of relevant AEs.

The cost of outpatient treatment was calculated based on the approved standard of primary health care for patients with malignant skin tumors, including melanoma, taking into account the four required outpatient doctor visits per year $[4,9]$.

All costs were calculated for the duration of BRAF-kinase inhibitors treatment until disease progression, obtained from the results of clinical trials. Therefore, the maximum course of therapy lasted up to 20 months [28, 33]. Due to the duration of treatment for more than a year, a discounting was performed using a rate of $3 \%$ when calculating the costs. 


\section{Results}

In view of the reported conclusion on comparable efficacy in terms of PFS, a cost-minimization analysis was assumed as the most appropriate method for assessing the investigated treatment strategies, and the first step was an analysis of costs related to the treatment of patients with BRAF-positive melanoma, i.e. costs of drug treatment with BRAF-kinase inhibitors, supportive care for $\mathrm{AE}$, and outpatient care.

\section{Cost Analysis}

Costs of drug treatment with BRAF-kinase inhibitors

In this pharmacoeconomic research, we have calculated the costs of drug treatment with drugs being compared per one month, two months, and one year of treatment, taking into account the cost of $1 \mathrm{mg}$ of active substance and dosage regimen in accordance with the approved prescribing information for the study drugs (Tables 3,4) [12,13].

Table 3. The calculation of costs of treatment with BRAF inhibitors

\begin{tabular}{|c|c|c|c|}
\hline INN & Dosage & $\begin{array}{c}\text { Total mg/ } \\
\text { day }\end{array}$ & $\begin{array}{c}\text { Cost of 1 mg, } \\
\text { RUB }\end{array}$ \\
\hline Dabrafenib & $\begin{array}{c}150 \text { mg twice } \\
\text { daily }\end{array}$ & 300 & 38.8 \\
\hline Vemurafenib & $\begin{array}{c}960 \text { mg twice } \\
\text { daily }\end{array}$ & 1,920 & 8.4 \\
\hline
\end{tabular}

Table 4. The calculation of costs of treatment with BRAF inhibitors per one patient

\begin{tabular}{|c|c|c|c|c|c|}
\hline INN & $\begin{array}{c}\text { Cost of } \\
\text { one treat- } \\
\text { ment day, } \\
\text { RUB }\end{array}$ & $\begin{array}{c}\text { Cost of } \\
\text { one-month } \\
\text { treatment, } \\
\text { RUB }\end{array}$ & $\begin{array}{c}\text { Cost of } \\
\text { 2-months } \\
\text { treatment, } \\
\text { RUB }\end{array}$ & $\begin{array}{c}\text { Cost of one } \\
\text { year of treat- } \\
\text { ment, RUB }\end{array}$ & $\begin{array}{c}\text { Decrease in } \\
\text { costs with } \\
\text { dabrafenib } \\
\text { treatment, } \\
\text { RUB (\%) }\end{array}$ \\
\hline Dabrafenib & 11,636 & 353,920 & 707,839 & $4,247,036$ & \\
Vemurafenib & 16,111 & 490,055 & 980,110 & $5,880,658$ & $\begin{array}{c}63 \%) \\
(28 \%)\end{array}$ \\
\hline
\end{tabular}

\section{Costs of supportive care for occurring adverse events}

Data on frequency of $A E$ based on the results of the retrieved clinical trials BREAK-3 and BRIM-3 were used in assessing the safety of alternative therapies within the comparison of treatment with dabrafenib vs vemurafenib (Tables 5 ) $[27,29]$. Cost of supportive care per each case of AE was calculated on the basis of approved health care standards and guidelines for their treatment. On the next stage of cost analysis the cost of AEs management has been calculated. In order to identify treatment regime for each $\mathrm{AE}$, treatment standards, recommendations and experts' opinion have been searched. Calculation of costs for correction $\mathrm{AE}$ was conducted only for AE III and IV grade of severity with frequency of each $A E$ $\geq 5 \%$ and was assumed that each type of $A E$ occurred only once in the year of treatment $[8,10]$. On the basis of received information, costs of AEs relief has been calculated and presented in Table 5 .
The data presented in Table 5 shows that the highest costs are associated with squamous cell carcinomas compared to treatment groups.

\section{Costs of Outpatient Care}

The costs of outpatient care in progression-free patients relate to the costs of diagnostic procedures and follow-up monitoring of disease progression. Costing of outpatient treatment was based on the standard of primary health care approved by Order of the Ministry of Healthcare of Russia No. 1143n dated December 20, 2012 [7], and included the costs of drug therapy, medical services, laboratory and instrumental diagnosis, calculated with tariffs approved by territorial funds of OMI in Moscow city [10]. Expenses on drugs included in the health care standard were established based on an average price of the auctions as a result of government procurement. The cost per one outpatient visit was 520 RUB. According to the Russian Society of Clinical Oncology 2014 guidelines, patients with melanoma must be monitored for disease progression once every three months [1]. Therefore, an average cost of outpatient care in progression-free patients over two months amounted to 347 RUB.

The total cost analysis took into account total expenses per one patient with unresectable or metastatic melanoma over two months. The cost of treatment was estimated in patients who were in a progression-free status, and required therapy with BRAF-kinase inhibitors (Table 6).

Table 6. Costs in progression-free period over two months, RUB

\begin{tabular}{|c|c|c|}
\hline Costs per cycle (2 months) & Dabrafenib & Vemurafenib \\
\hline Drug treatment & 707,839 & 980,110 \\
\hline Outpatient care & 347 & 347 \\
\hline AE & 34 & 75 \\
\hline Total over 2 months & 708,220 & 980,531 \\
\hline
\end{tabular}

Therefore, the data presented in Table 6 demonstrate that the therapy with vemurafenib requires more budget expenses. When assessing the cost of therapy in the two compared groups over the first year of treatment, the highest costs in the amount of 5,880,658 RUB were associated with the use of vemurafenib. Thus, the use of dabrafenib for the treatment of these populations of patients can reduce the state budgetary expenditure by $28 \%$ $(1,633,622 \mathrm{RUB})$ per patient within first year of the treatment (Table 7$)$.

Table 7. Costs in progression-free period over the first year of treatment, RUB

\begin{tabular}{|c|c|c|}
\hline $\begin{array}{c}\text { Costs per one patient per first year } \\
\text { in "progression-free state" }\end{array}$ & Dabrafenib & Vemurafenib \\
\hline Drug treatment & $4,247,036$ & $5,880,658$ \\
\hline Outpatient care & 2,080 & 2,080 \\
\hline AE & 205 & 448 \\
\hline Total per one year & $4,249,321$ & $5,883,186$ \\
\hline
\end{tabular}

Table 5. Cost of adverse events treatment occurring during treatment with dabrafenib in patients participated in BREAK-3 study

\begin{tabular}{|c|c|c|c|c|c|}
\hline \multirow{2}{*}{ Adverse event } & \multirow{2}{*}{ Cost of care per one case, RUB } & \multicolumn{3}{|c|}{ Frequency, $\%$} & \multicolumn{2}{c|}{ Cost of care for an adverse event considering its } \\
frequency, RUB
\end{tabular}


When establishing the costs of treatment with dabrafenib compared to vemurafenib, the probability of a patient's progression-free status during the entire treatment period should be taken into account, which was determined by the PFS value in patients treated with options being compared, based on the results of clinical trials BREAK-3, BRIM- 3 . The probability of being in progression-free state was estimated in each two months within the period. The choice of period for transition of patients into other states was based on published results of clinical trials. The parameter of probability was multiplied by the costs that were estimated within the appropriate period of observation of PFS $[28,33]$. Accordingly, while assessing the total cost of treatment until the progression based on $3 \%$ discount rate, it was estimated that dabrafenib treatment costs are 2,802,014 RUB and vemurafenib treatment costs are 4,335,476 RUB (Table 8). Therefore, when assessing the total costs of therapy in the two groups compared, it was demonstrated that the cost of therapy with vemurafenib is approximately 1.5 times higher than that with dabrafenib.

A more detailed estimate of the cost structure for the treatment of progression-free patients with unresectable or metastatic melanoma is presented in Table 8.

Table 8. Total costs for the treatment of patients with melanoma within the period before beginning of progression

\begin{tabular}{|c|c|c|c|c|c|}
\hline & $\begin{array}{c}\text { Months of } \\
\text { therapy }\end{array}$ & $\begin{array}{c}\text { Medication } \\
\text { costs, RUB }\end{array}$ & $\begin{array}{c}\text { Out-patient } \\
\text { care, RUB }\end{array}$ & $\begin{array}{c}\text { AE treatment, } \\
\text { RUB }\end{array}$ & $\begin{array}{c}\text { Total costs, } \\
\text { RUB }\end{array}$ \\
\hline Dabrafenib & $1-12$ & $2,782,149$ & 1,362 & 134 & $2,783,646$ \\
\hline & $13-20$ & 18,358 & 9 & 1 & 18,368 \\
\hline & Total & $2,800,508$ & 1,371 & 135 & $2,803,912$ \\
\hline Vemurafenib & $1-12$ & $4,050,013$ & 1,432 & 309 & $4,051,754$ \\
\hline & $13-20$ & 283,601 & 100 & 22 & 283,722 \\
\hline & Total & $4,333,613$ & 1,533 & 330 & $4,335,476$ \\
\hline
\end{tabular}

The data presented in Table 8 suggest that the most significant cost item is the cost of drug treatment with BRAF-kinase inhibitors, and they account for about $99.87 \%$ and $99.94 \%$ of the total cost in the dabrafenib and vemurafenib groups, respectively. However, costs of outpatient care and supportive care of occurring AEs account for less than $1 \%$ of total costs in both treatment groups. The expected budget saving with dabrafenib BRAF-kinase inhibitor in comparison with vemurafenib equals to $1,268,108 \mathrm{RUB}(31 \%)$ during the first year of treatment.

\section{Cost-minimization analysis}

As mentioned above, in view of comparable therapeutic (clinical) efficacy of the tested therapies, we decided to conduct the cost-minimization analysis, the main objective of which is to compare the costs required to achieve the same efficacy (Table 9).

Table 9. The results of cost-minimization analysis per patient on the respective treatment regimen with BRAF-kinase inhibitors within the period before the beginning of progression

\begin{tabular}{|c|c|c|c|c|}
\hline INN & $\begin{array}{c}\text { Drug treatment, } \\
\text { RUB }\end{array}$ & $\begin{array}{c}\text { Outpatient } \\
\text { care, RUB }\end{array}$ & $\begin{array}{c}\text { Supportive } \\
\text { care of AEs, } \\
\text { RUB }\end{array}$ & $\begin{array}{c}\text { Total } \\
\text { costs, } \\
\text { RUB }\end{array}$ \\
\hline Dabrafenib & $2,800,508$ & 1,371 & 135 & $2,802,014$ \\
\hline $\begin{array}{c}\text { Vemu- } \\
\text { rafenib }\end{array}$ & $4,333,613$ & 1,533 & 330 & $4,335,476$ \\
\hline $\begin{array}{c}\text { Cost differ- } \\
\text { ences }\end{array}$ & $1,533,106$ & 161 & 195 & $1,533,462$ \\
\hline
\end{tabular}

Cost-minimization analysis comparing total costs of the two studied BRAF-kinase inhibitors recommended by the Russian Society of Clinical Oncology for the treatment of unresectable or metastatic melanoma with BRAF V600 gene mutation showed that the use of dabrafenib, in comparison with vemurafenib, provides budget savings in the amount of 1,533,462 RUB per patient per course of therapy until the disease progression.

\section{Budget Impact Analysis}

The next step in the pharmacoeconomic research was to analyze the budget impact taking into account the projected number of patients with unresectable or metastatic melanoma. Thus, budget impact analysis carried out within the simulation of drug supply system covering the entire population of the Russian Federation was based on 1,245 patients who needed targeted therapy with BRAF-kinase inhibitors (Table 10).

Table 10. The results of budget impact analysis over a course of treatment with BRAF-kinase inhibitors until disease progression in 1,245 patients considering survival rates, RUB

\begin{tabular}{|c|c|c|c|c|}
\hline INN & Drug treatment & Outpatient care & $\begin{array}{c}\text { Supportive } \\
\text { care of AEs }\end{array}$ & Total \\
\hline Dabrafenib & $3,486,632,093$ & $1,707,323$ & 168,465 & $3,488,507,880$ \\
\hline $\begin{array}{c}\text { Vemu- } \\
\text { rafenib }\end{array}$ & $5,395,348,626$ & $1,908,047$ & 411,384 & $5,397,668,057$ \\
\hline $\begin{array}{c}\text { Cost differ- } \\
\text { ence }\end{array}$ & $1,908,716,534$ & 200,724 & 242919 & $1,909,160,177$ \\
\hline
\end{tabular}

Budget savings equal to $35 \%$ when dabrafenib is included in the treatment regimen for metastatic BRAF-positive melanoma will amount to 1,909,160,177 RUB over the entire course of treatment until the disease progression. In view of the identified high budget savings, an analysis of "missed opportunities" was carried out and showed that, within a fixed budget, switching to therapy with dabrafenib allows to treat additionally 680 patients with unresectable or metastatic melanoma with BRAF V600 gene mutation.

Meanwhile when budget impact analysis was conducted for the first year of the treatment per patient the difference in budget funds was estimated as $1,268,108 \mathrm{RUB}$, that showed the decline about $31 \%$ of required budget funds that was associated with the dabrafenib treatment in comparing with vemurafenib (Table 11).

Table 11. Results of current pharmacoeconomics study

\begin{tabular}{|c|c|c|c|}
\hline & $\begin{array}{c}\text { Drug treatment, } \\
\text { RUB }\end{array}$ & $\begin{array}{c}\text { Cost-minimiza- } \\
\text { tion analysis, } \\
\text { RUB }\end{array}$ & $\begin{array}{c}\text { Budget impact } \\
\text { analysis, RUB }\end{array}$ \\
\hline \multicolumn{4}{|c|}{ Results for first year of the treatment } \\
\hline Dabrafenib & 4247036 & 2783646 & 3465639376 \\
\hline Vemurafenib & 5880658 & 4051754 & 5044433562 \\
\hline Cost difference & $\begin{array}{c}1633622 \\
(28 \%)\end{array}$ & $\begin{array}{c}1268108 \\
(31 \%)\end{array}$ & $\begin{array}{c}1578794187 \\
(31 \%)\end{array}$ \\
\hline
\end{tabular}

\section{Sensitivity Analysis}

The two-factor sensitivity analysis was carried out to assess the robustness of the obtained results. Prices for the studied drugs (dabrafenib and vemurafenib) were selected to be the main variables, due to their high impact on the results of the study, as the cost of drug therapy for both treatment regimens accounts for more than $99 \%$ of total costs. With simultaneously increased price for dabrafenib and reduced price for vemurafenib by $21 \%$, the budget savings for dabrafenib versus vemurafenib were shown to retain, indicating that the obtained results are robust within the range of $\pm 21 \%$.

\section{Conclusions}

When analyzing the costs required per one year of therapy with the drugs being compared, it was established that treatment with dabrafenib, without survival rates accounted, was less expensive, when compared to vemurafenib, by $28 \%$, and the difference in the costs per patient was 1,632,622 RUB.

The budget impact analysis showed that dabrafenib therapy leads to reduction of budget expenditures by $31 \%$ in comparison with vemurafenib during the first year of the treatment. The estimated budget savings for using dabrafenib as compared to vemurafenib was about 1,268,108 RUB within the first year of the treatment.

Analysis of missed opportunities has demonstrated that throughout the projected cohort of patients (1245 patients), requiring BRAF-kinase inhibitors treatment, dabrafenib treatment allows to treat additional 680 patients in comparison with vemurafenib before progression within fixed budget. 
Therefore, in terms of clinical and economic analysis, the therapy with dabrafenib is the most preferable treatment option compared to vemurafenib for patients with BRAF-positive melanoma, as viewed from the public health system in the Russian Federation.

\section{References:}

1. Aliev M. D., Bohan B. Yu., Demidov L. V., Ivanov S. M., Samoilenko I. V., Trofimova 0. P., Kharatishvili, T. K., G. Kharkevich Yu. Clinical recommendations of the Association of Russian oncologists on the diagnosis and treatment of patients with

cutaneous melanoma/ 2014. P. 11

2. G. A. Frank, L. E. Zavalishina, T. V. Kekeeva, S. N. Aleksakhina, T. R. Garyfullina, A. 0. Ivantsov, N.V. Mityushkina, B. Pfeiffer, T. N. Strelkova E. N. Imyanitov. The first all-Russian molecular-epidemiologic- study of melanoma: results of analysis of mutations in the gene BRAF. J.: Archives of pathology, 2014, no.3, T. 76.

3. Kaprin A. D., Starinsky V. V., Petrova G. V. The state of cancer aid to the population of Russia 2014 //M.: fgbu mnioi. P. A. Gertsen" health Ministry of the Russian Federation. - 2015. - T. 235.

4. Mazurenko N. N. Genetic features and markers of cutaneous melanoma // Advances in molecular Oncology. - 2014. - №. 2. - S. 26-35.

5. Khabriev R.U., Kulikov A.Yu., Arinina E.E. Methodological basis of pharmacoeconomic analysis. Moscow: publisher "Medicine", 2011. - 128 pages.

6. Yagudina R.I., Babiy V.V. Methodological basics of effectiveness analysis of health technologies in pharmacoeconomic studies // Pharmacoeconomics: theory and practice. - 2015. - Vol.3, №1. - P.12-16

7. The Ministry of health and 1143H N from 20.12.2012 "On approval standard of primary health care in malignant the skin tumors (melanoma, cancer) stage I-IV".

8. The Ministry of health and 1126 N from 20.12.2012 "On approval standard of emergency medical care in pulmonary embolism"

9. The decree of the RF Government dated 28.08.2014 $871 \mathrm{~N}$ "About the adoption of rules of forming of lists of medicinal products for the medical application and the minimum assortment of medicinal preparations necessary for rendering of medical aid".

10. The tariffs of the Federal mandatory health insurance Fund Moscow 2015 11. Malignant melanoma of the skin. URL.2015: http://www.cancer.ic.ck. ua/ index_4_5.htm (reference date: 26.11.2015).

12. Instruction for medical use of vemurafenib. URL.2015: http://www.grls. rosminzdrav.ru (reference date:18.10.2015).

13. Instruction for medical use of Dabrafenib. URL.2015: http://www.grls. rosminzdrav.ru (reference date:18.10.2015).

14. Advanced melanoma. The real cost of Australian's national cancer. URL.2015: http://www.melanomapatients.org.au/wp-content/uploads/MPA_ the_real_cost.pdf (Reference date: 26.11.2015).

15. Alexandrescu D. T. Melanoma costs: a dynamic model comparing estimated overall costs of various clinical stages //Dermatology online journal. -2009. - Vol. 15. - №. 11.

16. Beusterien KM, Szabo SM, Kotapati S, Mukherjee J, Hoos A, Hersey P, et al. Societal preference values for advanced melanoma health states in the United Kingdom and Australia. Br J Cancer. 2009. Vol.101. №3. P.387-389.

17. Bos J. M., Postma M. J., Annemans L. Discounting health effects in pharmacoeconomic evaluations //Pharmacoeconomics. - 2005. - Vol. 23. - №. 7. - P. 639-649.
18. Brady M. S. et al. Melanoma and other skin cancers //Cancer Manage. 2011. - Vol. 14. - P. 1-32.

19. Chapman P. B. et al. Improved survival with vemurafenib in melanoma with BRAF V600E mutation //New England Journal of Medicine. - 2011. - Vol. 364. - №. 26. - P. 2507-2516.

20. Dabrafenib vs Dacarbazine. URL.2015:https://clinicaltrials.gov/ct2/show/ NCT01227889 (Reference date: 18.10.2015).

21. Drummond M. F. Methods for the economic evaluation of health care programmes. - Oxford university press, 2005.

22. Ferlay J, Shin HR, Bray F et al. (eds) GLOBOCAN 2008 v1.2, Cancer Incidence and Mortality Worldwide: IARC CancerBase no. 10 (Updated December 2010). Lyon,France: International Agency for Research on Cancer 2010.

23. Flaherty K. T. et al. Surrogate endpoints for overall survival in metastatic melanoma: a meta-analysis of randomised controlled trials //The Lancet Oncology. - 2014. - Vol. 15. - №. 3. - P. 297-304.

24. Giblin A. V., Thomas J. M. Incidence, mortality and survival in cutaneous melanoma //Journal of plastic, reconstructive \& aesthetic surgery. - 2007. Vol. 60. - №. 1. - P. 32-40.

25. Grob J. J. et al. Patient perception of the benefit of a BRAF inhibitor in metastatic melanoma: quality-of-life analyses of the BREAK-3 study comparing dabrafenib with dacarbazine //Annals of Oncology. - 2014. - Vol. 25. - №. 7. - P. 1428-1436.

26. Hall H. I. et al. Update on the incidence and mortality from melanoma in the United States //Journal of the American Academy of Dermatology. - 1999. - Vol. 40. - №. 1. - P. 35-42.

27. Hauschild A. et al. Dabrafenib in BRAF-mutated metastatic melanoma: a multicentre, open-label, phase 3 randomised controlled trial //The Lancet. 2012. - Vol. 380. - №. 9839. - P. 358-365.

28. McArthur G. A. et al. Safety and efficacy of vemurafenib in BRAFV600Eand BRAFV600K mutation-positive melanoma (BRIM-3): extended follow-up of a phase 3, randomised, open-label study. -2014.

29. McArthur G. et al. Dirk Schadendorf1, 2, David E. Fisher3, Claus Garbe2, 4, Jeffrey E. Gershenwald5, Jean-Jacques Grob6, Allan Halpern7, Meenhard Herlyn8, Michael A. Marchetti/ Nature reviews disease primers - 2015.-Vol.1. 30. Robert C. et al. Improved overall survival in melanoma with combined dabrafenib and trametinib //New England Journal of Medicine. - 2015. - Vol. 372. - №. 1. - P. 30-39.

31. Srivastava K. et al. Systematic Review and Indirect Treatment Comparison of Dabrafenib and Trametinib versus Other Treatments Used in Previously Untreated Metastatic Melanoma Patients //Journal of Clinical \& Experimental Dermatology Research. - 2015. - Vol. 2015.

32. Styperek A, Kimball AB. Malignant melanoma: the implications of cost for stakeholder innovation. Am J Pharm Benefits 2012; 4: 66-76.

33. Tafinlar Poster presented at ESMO 2014, Abstract 1092PD.

34. American Cancer Society. URL.2015: http://www.cancer.org/Cancer/ SkinCancer-Melanoma/OverviewGuide/melanoma-skin-cancer-overview-diagnosed.American Cancer Society 2012.pdf (Reference date:17.02.2016).

35. Dabrafenib clinical trials. URL.2015: https://clinicaltrials.gov/ct2/show/ NCT01597908 (Reference date: 18.10.2015).

36. Melanoma and Other Skin Cancers. URL.2015: http://www.cancernetwork. com/cancer-management/melanoma-and-other-skin-cancers (Reference date:17.02.2016).

37. Vemurafenib vs Dacarbazine. URL.2015: https://clinicaltrials.gov/ct2/ show/NCT01006980 (Reference date: 18.10.2015) 